\title{
TECHNOLOGICAL INNOVATION AND NEW PRESENTATION STRATEGIES FOR VIRTUAL MUSEUM EXHIBITIONS
}

\author{
S. Chiarenza ${ }^{1 *}$, A. R. D. Accardi ${ }^{1}$, R. Inglisa ${ }^{1}$ \\ ${ }^{1}$ Department of Human Sciences and Promotion of Quality of Life, San Raffaele Roma Open University, Rome, Italy - \\ (stefano.chiarenza, aldo.accardi, rosalinda.inglisa)@unisanrafaele.gov.it
}

Commission II, WG II/8

KEY WORDS: Exhibition Design, Ontology, Virtual Modelling, Virtual Museum, Museum of Architecture

\begin{abstract}
:
In recent years, the theme of museums and virtual exhibitions has been the subject of a wide debate and a significant number of researches and experiments. In a vast and articulated framework of experiences, this article intends to highlight new strategies related to the creation of digital museum paths based on a multidisciplinary approach. The research presented here intends to create a protocol for the construction of digital museums based on the definition of an ontology capable of integrating digital elaborations of 3D virtual models and exhibition projects with semantic relationships. The experimentation conducted has considered, in particular, some issues concerning drawn architectures. Thanks to a rigorous methodological approach and the use of new technologies for virtual and augmented reality, it has been possible to build a tool that allows improving the knowledge of the cultural heritage investigated through the customizable structuring of virtual exhibitions. It is a tool that, thanks to its flexibility and precision, can satisfy the widest user target, ranging from experts (professionals, designers, historians, researchers, etc.) to simple visitors (tourists, enthusiasts, etc.).
\end{abstract}

\section{INTRODUCTION}

In recent years, the theme of museums and virtual exhibitions has been the subject of a wide debate and a significant number of researches and experiments (Albisinni and Ippoliti, 2016). The recent developments that have affected the museum practice have challenged the very definition of the term museum. In 2007 the International Council of Museums (ICOM) defined the museum as "a non-profit, permanent institution in the service of society and its development, open to the public, which acquires, conserves, researches, communicates and exhibits the tangible and intangible heritage of humanity and its environment for the purposes of education, study and enjoyment." (ICOM, 2007). In this way, the Council opened up to the possibility of communicating and showing tangible and intangible assets of the heritage with greater incidence compared to 2001. Today, a new definition is being discussed to include, among other things, "the commitment of museums to be meaningful meeting places and open and diverse platforms for learning and exchange" (ICOM, 2019).

This consideration highlights the growing importance of studying new scientific paradigms more suitable to deal with the complex changes linked to musealisation, including also digital technologies for the creation of active learning processes.

In a vast and articulated framework of experiences, this article intends to highlight an experimentation related to the creation of digital museum paths based on a multidisciplinary approach. This approach, related to the digitization of information, is fundamental as it allows to increase the semantic associations of which cultural heritage, in general, is already particularly rich. New strategies for presenting cultural heritage are also developed through the implementation of virtual exhibitions.

The research carried out to date has been aimed to establish a protocol for the creation of digital museums. This experiment focused mainly on intangible urban architectures and contexts. Specifically, these are architectures and spaces drawn and never built, or architectures built but destroyed and therefore disappeared. This choice was related on the one hand to the possibility of separating the exhibition from the artistic object, and, on the other, to that of offering an exhaustive knowledge and experience of assets that are not otherwise usable, since they are non-existent but part of intangible heritage. In fact, if the virtualized exhibition of material cultural heritage must necessarily coexist with the assets themselves (even for example in the case of archaeological architectural heritage), in the case of assets that do not already have a material consistency, the virtual museum exhibition can also be completely independent of the object.

The only link with the object (i.e. a painted image, a project drawing, a photographic image, etc.) is the scientific validity of the starting graphical model, through which it is possible to reconstruct the architectures and spaces investigated with a good degree of precision. This study also explains how it is possible to identify new strategies for creating virtual museum exhibitions and to expand the tools to present virtual and real collections (which include drawings and photographic material, as well as models and other objects) applying new technologies. Moreover, this research is aimed to create a museum ontology through a multidisciplinary approach, in order to combine a considerable amount of information and to allow a wide interoperability. The intent is to define a good practice in the creation of virtual museum exhibitions using ICT technologies not only for the management of cultural heritage resources but above all for the enhancement of the heritage, in particular of the architectural one, based on the experience and recent literature on the subject. The present paper in section 2 analyses drawn architecture and spaces - real or imaginary; in section 3 it shows how to create a museum ontology; in section 4 discusses the problems related to the representation of the heritage, while in section 5 it deals with the problem of defining virtual exhibitions. Finally, section 6 presents the conclusions of the study.

\section{NON-EXISTENT DRAWN ARCHITECTURES: INTANGIBLE ELEMENTS OF CULTURAL HERITAGE}

Within the cultural heritage a significant role is played by all those works - e.g. drawings, paintings, photographic images, etc.which directly or indirectly bear witness to the presence of architectures or urban spaces that do not exist.

\footnotetext{
* Corresponding author
} 




Figure 1. Città ideale (detail), Galleria Nazionale delle Marche, Urbino 1470-1490 c.

In fact, they make us aware of an intangible heritage inasmuch as it never materialized in reality, that is realized but lost. In many cases, we are dealing with purely imaginary elements. In others, they are real design prefigurations codified in rigorous graphical models. The theme of non-existent drawn architectures is certainly fascinating and has often aroused the interest of scholars and the public (Smith, 2014) and (Sanders, 2014). It is precisely for this reason that it is an important resource in the processes of heritage enhancement and leaves room for unprecedented dissemination possibilities. The sources related to this subject can be traced back essentially to three types of documents: pictorial or similar iconographic representations; prints with different techniques (etchings, engravings, etc.) with an architectural or urban subject; architectural representations - mostly drawings - relating to unrealized or no longer existing works (for example in architectural treatises, in project graphics, etc.). To these, we can currently add photographic images through which it is also possible to have evidence of missing works, even though they are not proper drawings. All these documents are characterized by the presence of architectures, urban contexts, architectural elements that are suitable for being observed, read, analysed on several levels and which constitute in all respects an intangible heritage. They are in fact existing, but unexplorable beyond the limits of the work to which they belong, and their use is linked exclusively to the view in which they are relegated.

From a historical point of view, drawn architectures present different possibilities of approach. One is the purely philologicalinterpretative one that looks for cultural and artistic relationships of the represented architectures, aiming at the integral knowledge of a cultural area or a historical period. A second approach is that of a more strictly iconological type which, going beyond the artistic interpretation, focuses on the characteristics of the architecture represented, seeking out the generative elements and underlying theoretical frameworks.

This means that the philological-interpretative approach considers these representations as evidence of a cultural environment and of a precise period, and allow the reconstruction of episodes from the history of an era on the basis of precise and concrete data, whilst the iconological approach considers the representations of those architectures as proofs, in the most literal sense of the term. In other words, the image becomes an essential element for the reconstruction of a work, be it a real representation or just an imaginary one, providing a variety of elements not only related to the formal configuration but often also related to its uses (Burke, 2002).

Particularly in the pictorial production from the fifteenth century onwards, the presence of architecture is often a pretext for an authentic design experimentation, besides being an indisputable element of perspective exercise. Such are, for example, representations of ideal cities, now symbolic images of the Renaissance, in the well-known tables of Urbino (Figure 1), Baltimore, and Berlin, in which the authors, still unknown, have outlined refined models of spatial articulation. Or, similarly, the innumerable sixteenth-century architectural prefigurations present in frescoes, paintings, and wooden inlays (Figure 2).

This repertoire then also includes all the city views that, from the mid-seventeenth century, became an independent pictorial genre. Consider the views of the cities of the Netherlands, from Amsterdam to Delft and Haarlem and then, in the eighteenth century, with Canaletto and Bellotto, those of Venice, Dresden, Vienna, and Warsaw, just to mention the most striking examples. Significant are also the inventions of the quadraturist painters and of the architects and scenographers who staged fantastic architectural and spatial structures between the end of the seventeenth century and the eighteenth century (Argan, 1983).

Of course, it is impossible to think of any objective iconological analysis on the architectures represented if the representation itself does not offer a scientific model of analysis. And it is for this reason that it is possible to go into in-depth analysis and reconstructive readings only for the depictions based on rigorous graphic and geometric codings. With this we do not want to deny the importance of non-scientific figurations in the context of historical reconstructions, however, the presence of scientific elements in the figuration -rendered in perspective, in orthogonal projections or in other rigorous forms of geometric constructionallows better reliability and adherence to the source.

The perspective, in particular, from the examples of the Renaissance to the late eighteenth century, stands as a method of objective representation of space and it is suitable as an elective instrument in the art for the representation of all the elements of the anthropic landscape; the innovative devices developed from the seventeenth century onwards, such as the optical camera or the pantograph, also allowed a perfect fidelity of the perspective representations to the existing one. Not surprisingly, thanks to the paintings of Bernardo Bellotto it was possible to reconstruct the old city of Warsaw, razed in 1944, during the Second World War (McCouat, 2015).

Finally, the graphical models of orthogonal projections are objective documents in which the biunique relationships between drawing and object are such as to make complete reconstructions of the drawn object possible.

The images of the cities and of the architectures drawn are, therefore, still today an inexhaustible mine of information worthy of being decoded and organized. Indoor and outdoor environments, arcades, architectural backdrops, etc. form a real corpus that opens today considerable exploratory possibilities thanks to ICT, becoming an important musealisation object.

These images allow readers to imagine the appearance of a city for which objective glimpses are offered, to savour an urban ideal or often a simple 'whim' that has had no life beyond the drawing board. On the other hand, they occupy historians in intense interpretative work. The images, in many cases, must, in fact, be carefully connected with a large number of other documents to be cleaned of incorrect and untruthful messages. 


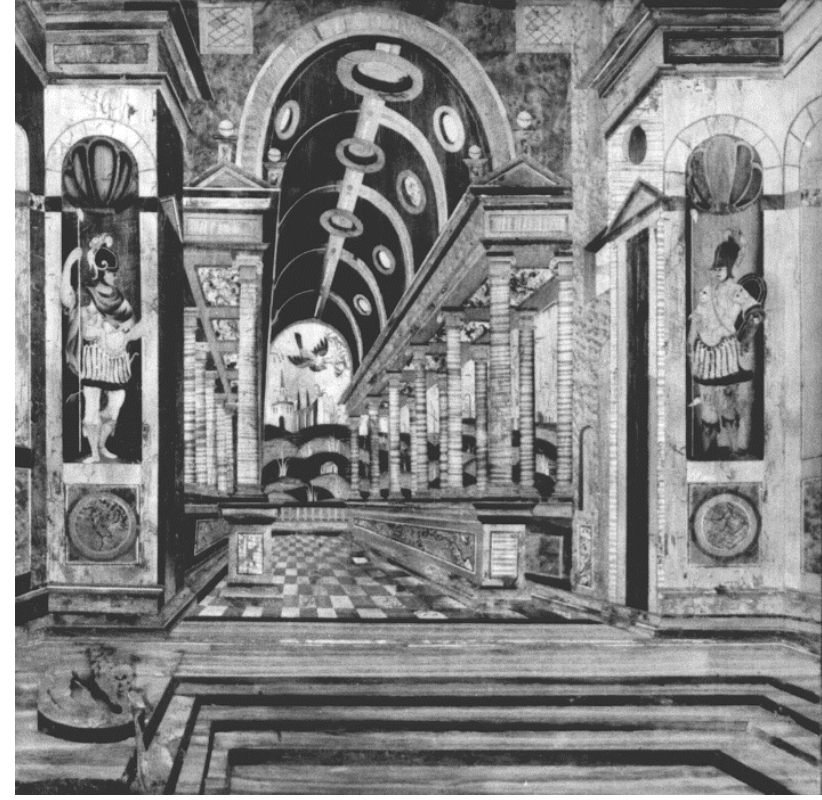

Figure 2. G.B. Vigilante, N. Ferraro, L. Ducha, T. De Vogel, wooden marquetry with architectural subject, Cerosa di S. Martino, Napoli 1590 c. (C) Soprintendenza BBAA Napoli

In fact, some representations often sacrifice verisimilitude in favour of beauty, or they prefer illusion to reality (Figure 2). Scholars must, therefore, be able to explain in an exhaustive and precise way, with the use of documentary accuracy and historical vision, the complex and fascinating reality behind every representation.

In the context of research aimed at experimenting with new strategies for presenting virtual exhibitions, attention to the vast repertoire of drawn architectures was a strategic choice. In fact, for the characteristics described above, these sources need to relate to a large number of other documents making significant the definition of a multidisciplinary approach and the use of the construction of an ontology able to bring together information and basic tools necessary for research. The possibility of creating a container of digital data makes it possible to open new windows of knowledge allowing to connect and correct data in a short time and to communicate in a complete and effective way a given theme.

The first experiments carried out had as their object some late mannerist architectures represented in perspective on prints from engravings in treatises on architecture, or eighteenth-century perspective representations with architectural subjects made for theatre sets. However, beyond the specific objects of study, they have demonstrated the replicability of the construction of an ontology connected to virtual museum paths also on similar subjects belonging to the same macro repertoire.

\section{RESEARCH FOR THE CREATION OF A DIGITAL MUSEUM ONTOLOGY}

ICT and its increasingly precise applications constitute an important resource in the definition phase of a virtual museum. They make it possible to support cultural heritage management processes in an unavoidable way today, also offering new possibilities of fruition and therefore of enhancement.

The abundance of semantic associations required by a virtual museum, as observed in the previous paragraph, can only be satisfied by the creation of an ontological resource capable of incorporating and relating a large quantity of digitized data. These data can also be of different nature and can be stored, checked and corrected with extreme speed and accuracy.
Simultaneous management of different document systems also facilitates comparison operations. Such a resource can also easily enable interoperability by the research community as well as data population and collaborative management.

It seems pleonastic here to return to the different definitions of ontology and the role of ontology itself (Neches et al., 1991) and (Gruber, 1993) and (Borst, 1997) and (Guarino, 1998) and (Studer et al., 1998). However, attention must be focused on the use of ontological models for the integration of cultural heritage information. According to Biagetti, in fact, "ontologies are the fundamental tools for achieving semantic interoperability since they conceptualize a domain and act as mediators for the integrated research of digital objects managed in different repositories" (Biagetti, 2016, p. 44). The literature on ontologies is very extensive and debated (Corcho et al., 2007), as well as their use in the management of cultural heritage (Hernández, 2008). However, although these are often very broad initiatives, they were mainly focused on historical-artistic or managerial aspects, for example, of complex territorial data (Noardo, 2016). The creation of these resources, also linked to the use of web semantic technologies, although it paved the way for different types of experimentation, still appears isolated with respect to virtual museum design processes in the strict sense.

The present research instead wanted to structure an ontology more directly related to the creation of virtual exhibitions and, at the same time, being able to relate not only with archives, libraries and museums scattered around the world but to contain visual paths that are always modifiable and customizable. The goal is to allow the user to visit virtual exhibitions by accessing the works, viewing the virtual paths to get to know them (in this case the non-existent spaces of the drawn architectures) and, thanks to all the possible semantic associations made available by the ontology, knowing the cultural context and, more generally, the space-time context of the works.

The user will then be able to query text databases, through specific search keys, or even visual databases by consulting archives of digital images related to the resources explored. Therefore, it is a tool that, thanks to its flexibility and precision, can satisfy the widest user target, ranging from experts (professionals, designers, historians, researchers, etc.) to simple visitors (tourists, enthusiasts, etc.).

A complex semantic resource structured in this way must necessarily make use of a multidisciplinary approach. The aim of our study was then to propose a general method to define, populate and manage this ontology. The first step of the research conducted was to analyse the state of the art related to the ontologies focused on cultural heritage. On this basis, we defined the objectives to be achieved. Recent studies have shown how the ability to manage and integrate rich and diversified contents thanks to ontological models is an added value that can improve distribution and interoperability compared to traditional approaches (Hyvönen, 2012). However, although there is much research in this direction, there are still few ontological resources that can fully exploit the potential of the semantic representation of information.

In order to create digital museum paths containing images, sounds, three-dimensional models and canonical document databases, the main concepts of ontology were defined and then reapplied to areas whose development was assigned to domain experts. In this specific case, some key areas were identified, such as the historical-artistic one, the digital representation one, and the museum exhibition one. The various concepts were then nested within the different areas. The data can be recalled through keywords related to author, work, artistic current, historical period, time span, etc. For space-time information, some works already proposed in sector research were taken into consideration (Signore and Bartoli, 1990) and (Signore et al., 1997). 


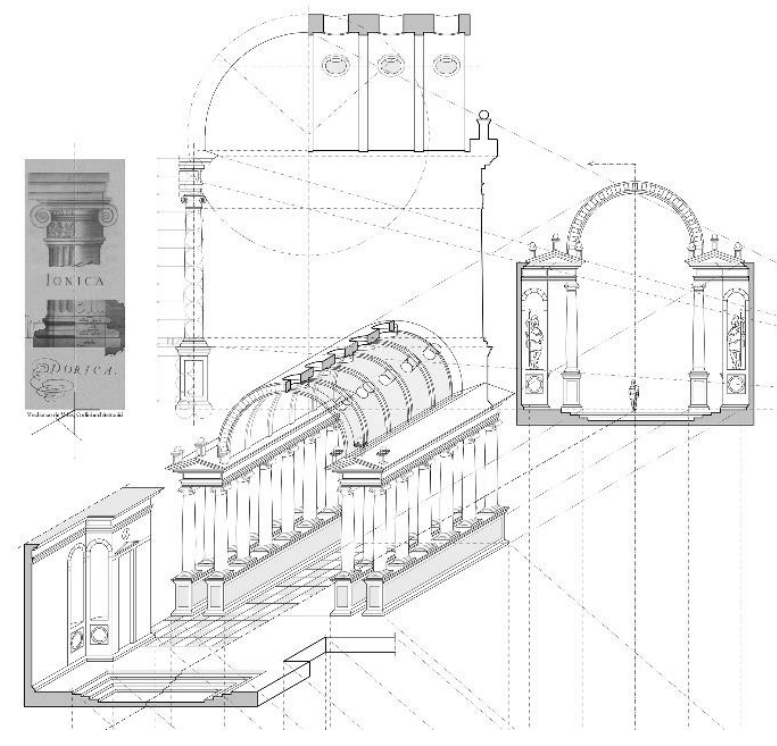

Figure 3. Axonometric reconstruction of the imaginary architecture drawn in figure 2 (Drawing by S. Chiarenza)

Even digital representations are among the possible instances. The files related to digital modelling can be stored directly in the ontology. Using technologically advanced tools, it is, therefore, possible to offer users a wide and rich experience of the investigated heritage. The concepts present in the area of exhibition design are an innovative element in the panorama of ontologies on cultural heritage. Through these concepts, we have tried to make the creation and customization of museum paths possible. These can be based, for example, on the work, on the place or only on specific subjects contained in the work.

The description of the constituent elements of the museum path within the ontology will allow saving, in addition to the work, also the type of museum design so that it can also be applied to instances added later. To this end, the concepts of the different areas have been linked together through properties (object property).

The ontology defined in the research has been named DMO (Digital Museum Ontology) and its complete structuring is currently still in progress. However, it has been tested considering some themes related to drawn architecture and the outcomes can be considered encouraging, although not yet published. And therefore, it is considered useful in this phase to be able to illustrate, albeit briefly, the methodological structure able to open new strategies for the presentation of virtual exhibitions.

\section{METHODS OF REPRESENTATION OF THE INVESTIGATED HERITAGE}

In the process of defining a virtual museum itinerary, the graphicvisual sources are documents of primary importance. The experiences of digital repositories of graphic material (drawings, paintings, prints, photos, etc.) have become very frequent in recent years. More and more libraries and museums have implemented, in their web platforms, large sections dedicated to visual sources which are accessible online. Consider, for example, the Biblioteca Digital Hispánica of the Biblioteca Nacional de España, the Banque d'Images of the Gallica - Bibliothèque Nationale de France, or even the digital visual collections of the Metropolitan Museum of New York, to name just a few of the most significant ones. Furthermore, digital library network projects, such as Europeiana, are becoming increasingly popular, sharing not only texts but also visual documents.

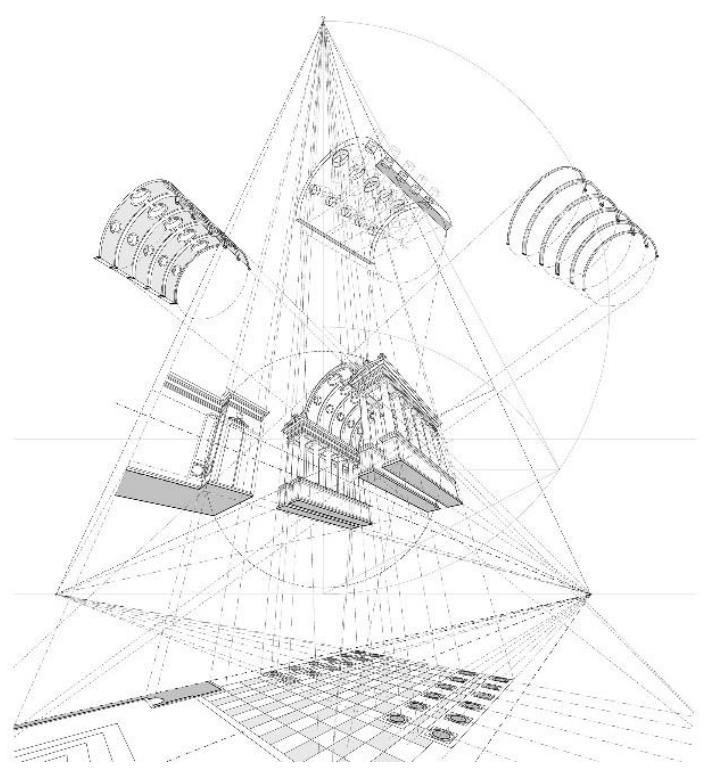

Figure 4. 3D view from the digital model of the imaginary architecture drawn in figure 2 (Drawing by $\mathrm{S}$. Chiarenza)

However, the availability of easily accessible graphic material does not necessarily imply an immediate understanding of the works collected, nor does it imply the possibility of creating direct paths of knowledge.

As for graphical documents containing drawn architectures, for example, it is often important to be able to reconstruct the works and make them usable. This is possible only thanks to a careful work of graphic interpretation that allows, first of all, to decode the compositional logic at the base of the structure of the space and to grasp its qualities, beyond the simple metric definition. The drawing represents the priority moment of analysis of the architectures or urban contexts depicted (Cardone, 2014). The latter then takes shape, in a gradual process of cognitive appropriation, even if only in a digital environment. Starting from the analysis of existing graphical documents, it is possible to reconstruct three-dimensional solid models, especially when it comes to scientific representations that respond to rigorous methodological approaches.

Thanks to the possibilities offered by infographic drawing, it is possible not only to accurately analyse the drawing but to create virtual models of the represented works, offering a total and completely new visualization. These models are in fact able to restore also the spatiality of the drawn architectures or the urban contexts in which they are located. Spatiality is in fact often implicit, in the case for example of drawings in orthogonal projections or delegated to a foreshortening linked to a certain point of view, as happens in the perspective examples.

The nature of the original documents defines the different approach to reconstruction. In fact, if the sources are scientific drawings, the construction of the model can be performed by obtaining metric-dimensional data directly (orthogonal projections) or indirectly (perspective). In the first case, it is a matter of constructing a model analogous to what could be done in a material-type construction (Messina and Chiarenza, 2015). In the second case, it is instead necessary to resort to geometricdescriptive reverse procedures that allow reaching first the definition of the orthogonal projections of the object (Giordano, 2014) and (Pascariello, 2009) and secondly to its modelling.

In most cases, however, the graphical documentation of a scientific nature is inadequate and it is, therefore, necessary to resort to critical interpretations of the documents (Figures 3-4). 


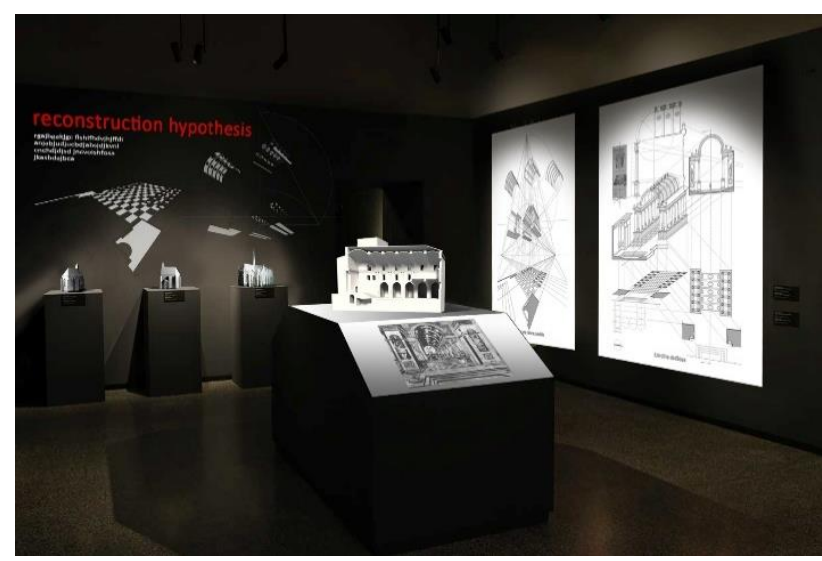

Figure 5. Virtual exhibition. One of the hypothesis of drawn architecture reconstructions (virtual exhibition by A.R.D.

Accardi, 2019, drawings by S. Chiarenza)

This is the case, for example, of non-rigorous perspective iconographic representations (in which it is necessary to cross geometric results with data deduced from historical-documental analysis) (Chiarenza, 2006), or from photographic representations that need more specific photogrammetric processing.

Of course, to the definition of the graphical models contributes a great variety of competences that allow acquiring in them a set of references that go beyond the pure description of the geometricmorphological aspects of the objects represented. It is, in fact, a question of bringing together within the virtual model a set of knowledge relating to history, materials, construction techniques, and technologies, etc.

The virtual model thus described is certainly one of the most widely used tools for spreading the space-time knowledge of a building to the public. However, the possibilities it offers today are many (Kersten et al., 2017). The models are generally dynamic and interactive, allowing the visitor to go along the interior and exterior space, thus making real what was only an imaginative or design prefiguration in the drawing. Yet they are very versatile and can be structured in different ways. Realistically characterized, they evoke the complexity of material and immaterial qualities of the architectures they represent as if they existed. Treated in a conceptual manner (Sirbu, 2003), they can make visible hidden properties such as structural features, specific construction techniques, geometrical matrices hidden in the architectural composition, etc. Furthermore, more and more often virtual models become vectors of the so-called immersive reality, a bridge between informative, educational and entertainment intentions.

As part of the research carried out, the work of geometric interpretation of images and modelling played a key role. The intent was in fact to create a series of virtual models of the drawn architectures belonging to a specific work or collection of works. These models were then characterized by a series of information and were made to converge, in the form of files, within the DMO ontology, becoming part of the flow of data in the archive (Figure 5).

\section{NEW STRATEGIES FOR VIRTUAL MUSEUM EXHIBITIONS}

This experimentation about a new type of approach to the creation of digital museum exhibitions gained through the development of new technologies using virtual reality and 3D experiences, it allows a new active approach of the population and offers the richest involvement of users. The new way to use the systems of virtual communication in the field of cultural heritage includes emotive exhibitions, indoor and outdoor, with communicative and special tools in order to create "narrative experiences' which integrate objects, contexts, histories aimed in order to involve emotionally the audience (Bowen, 2000).

Nowadays all museums and exhibitions design have the opportunity to host innovative multimedia and ICT systems in their exhibitions, as virtual and augmented reality and storytelling authoring. The creative use of virtual tools in exhibitions allows museums to change the way of presenting objects and communicate their meaning, i.e. showing artifacts in their context (real and virtual), but even to explain complex ideas, increasing opportunities for interactivity, providing to the visitor exiting and involving experience. In order to verify and validate the developed technologies for the proposed method, it needs to apply this method in several cases studies and not only specific one (Patel et al., 2003).

In the specific case, the creation of digital museum paths is aimed at defining new ways of understanding architecture and urban contexts that have been drawn (planned), perhaps never built, left unfinished or even destroyed and, therefore, disappeared. Such an operation involves the use of special technologies, which not only contribute to the definition of the exhibitions themselves but expand the presentation tools of the collections, both virtual and real. However, the methods of structuring the museum paths that are the subject of this study, with digital resources and dynamic databases, in line with the most recent guidelines for the improvement and broad accessibility to knowledge of cultural heritage - in this specific case of lost architectures - are moving in a field of research that is still evolving.

The accessibility we refer to is not to be considered only physical, but above all "visual", that is the origin of all mental "accessibility" (Ruggieri Tricoli, 2013); but it is also accessibility understood as the "quantity of information that can be received from the asset [...] with which one comes into contact" (Quagliolo, 2002, p. 14). What is certain is that there is no obligation to make any shred of heritage "visible" to the communities, however, it can be useful to be aware that these cultural and architectural assets have existed or that they have simply been "thought". In these cases, the so-called "visibility" can be achieved through different museographical strategies applied in situ (real) or in "virtual" contexts.

In our case, the "materialization" of these lost architectures - never built or incomplete - combined with the image they would have had or have had in the past, increases their communicative potential. Today the exhibition design has achieved total compositional freedom, supported by the latest technological know-how, thus overcoming the physical limits to virtuality. The support provided by virtual technologies is necessary to give back to contemporaneity what "has been" or has remained in the status of "drawing" (i.e. not realized), and for these reasons requires a reconstruction of the original contexts of use and origin. It is not just a reverse perspective and a mere redrawing, but a cultural mediation to increase the value of the work of art and its understanding, making it more attractive to the public (Accardi, 2011).

Starting from the study and the elaboration of some graphic documentary supports, such as, for example, the project of a building that no longer exists or has never been realized, it would be possible to reconstruct its interiors, even including furniture and furnishings, as they should have been in the historical period of reference and obtaining the same surprising effect generated by the so-called Period Room, in which every visitor could approach the desired level of in-depth study of the theme, using a digitalized database and a series of multimedia and interactive instruments. The use of digital technologies transforms the visit experience into "immersive" involvement, into a cultural and educational experience, in which the user becomes a spectator, activating entertainment and learning processes. 


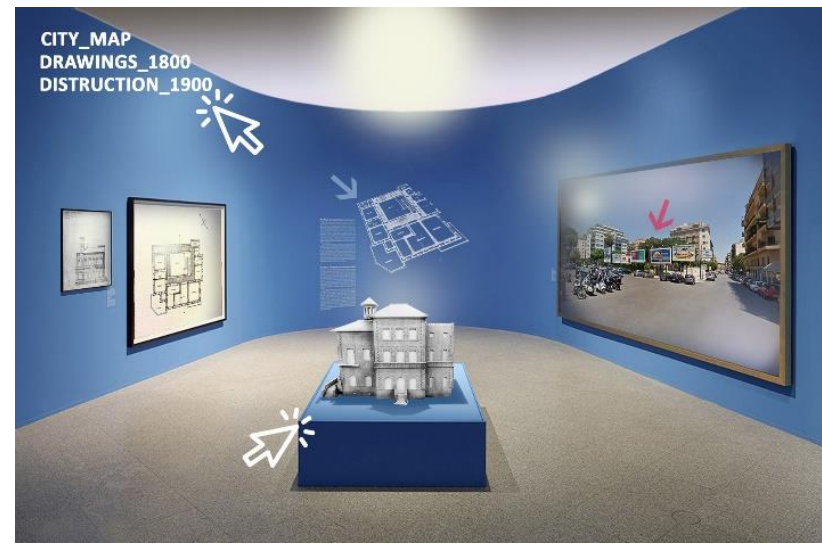

Figure 6. Virtual exhibition with different tasks about any possible thematic insight, personalized by users: the exhibition proposes the reconfiguration of a disappeared historic building (virtual exhibition by A.R.D. Accardi, 2019)

Inspired by the variety of the contents of the database, the creative project could also include the subdivision into various themes, such as the architectural style, the social and cultural context, the history of the city and its evolution, its characters, the graphic representation and realization techniques of projects, etc., in an atmosphere of sensory experimentation to be experienced in this "exceptional" virtual context (Figure 6).

The public could thus have a clear image of the building, of its construction systems, of its spatial quality, as well as of the design skills of those who conceived it and, last but not least, have the opportunity to experience it as if it still existed and perhaps discover the daily lifestyles of those who lived in those architectures. Thus, the "Virtual Heritage" to which we refer has a much more representative and evocative meaning that goes far beyond "digital culture": according to our methodological approach, it is the processing of information associated with the asset that changes its character, interpretation, and value. We could say that the ultimate goal of virtual processing is the perceptive and cognitive increase of the thing-cultural asset as virtual heritage, digital access to the virtuality of cultural information (Figure 7).

Although virtuality represents an important way to enrich the visit, it is necessary to consider that the public still requires to see the objects in person, experience them actively, in an interactive and creative way, and, by responding to these specific moments, it is also possible to make the visitor interact with that part of urban fabric in which the "reconstructed" architecture was inserted, and to evaluate the appearance of its mass of origin, its proportional and relational relationship both with the context and with the surrounding architectures.

The use of an ICT system in the outdoor environment would also allow to put the "lost" architecture in connection with other similar buildings, in terms of style and conformation, so that, among places, stories, and legends, it is possible to structure a link between what remains and what no longer exists, in the general framework of knowledge of a portion of the city's history. Such ICT solutions would allow the visiting public to increase knowledge of the various topics even during the indoor experience, as they could converge a series of digitized data, including historical photos, videos, maps, projects, drawings, film stories, editorial publications, etc. in that database or open source platform mentioned above. This system would also make it possible to create and plan one's own tour itinerary to be carried out not only in a "virtual" way in an indoor environment but as a guide to the "physical" exploration of the city (Figure 8).

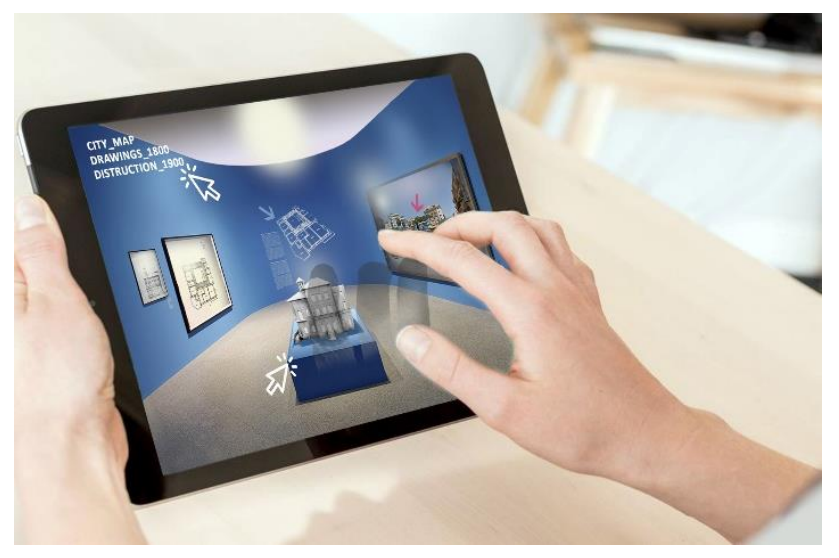

Figure 7. The image shows the way to use a hypothetic app with which the user can immerse himself in the virtual exhibition and have all the desirable information (graphic design by A.R.D. Accardi, 2019)

The networked system, as well as providing a public entertainment and cultural dissemination service, could be used as a tool for monitoring both the entire system of architectural heritage and the individual parts, since it will be able to gather comments and suggestions from the visiting public, but also to monitor the physical and environmental conditions in which historical architectures are inserted. With virtual exhibitions, it is possible to reconstruct, multiply and reassemble new contexts, add new cognitive and communicative tools that initiate different and broader learning processes.

The museum exhibition, in general, but perhaps even more if virtual, is able to "reconstruct" what is scarcely legible, to recontextualize what is fragmentary, dispersed, isolated or hidden, to restore the cultural thematic links of a cultural asset, to multiply and reassemble the tools of knowledge.

The virtual exhibition can, therefore, be considered an extension of reality and in some ways an enhancement of it, since it combines, in cognitive processes, perceptive and experiential aspects with the interpretative and symbolic aspects of meaning (Sabbatini, 2003). Through the virtual exhibition, we can actually re-establish the network of relations that connect the cultural object to its context of origin, to the territory, to the anthropological, historical, philosophical and social, technical and artistic themes of which the object is an expression.



Figure 8. The image shows the use of the application in the outdoor environment, which helps to visualize the architecture (no longer existent) in its original context (graphic design by A.R.D. Accardi, 2019) 
In designing a virtual reality system for communicating a cultural context to the public, it is essential to associate the language and the metaphors of the virtual to the knowledge of historicalartistic-technological contents, the possible ways of interacting with the contents and finally the potential that digital technologies are able to develop in comprehension, perception, interpretation, and simulation. If we disregard one of these aspects, we will not be able to create an effective communication project (Accardi, 2019).

\section{CONCLUSION}

The research described intends to implement new strategies to present virtual museum exhibitions. Based on the already consolidated experiences of ontological resources related to cultural heritage, the article wanted to highlight some possibilities of implementation. Thanks to a multidisciplinary approach, we have succeeded in structuring a resource of knowledge (DMO - Digital Museum Ontology) able to integrate files of three-dimensional digital models and museum exhibition projects with semantic relationships. The three-dimensional virtual models, together with the other documents present in the archive, can then be accessed within selectable virtual museum paths. The museum itineraries can also be modified by the user, thus personalizing their own visiting experience.

The tested and described tools, thanks to the huge amount of information they collect and link, can be exploited both in educational, training and entertainment contexts, both in professional and research fields.

\section{ACKNOWLEDGEMENTS}

The experimentation of the multidisciplinary methodological approach has been carried out by the research group on virtual museums of the Department of Human Sciences and Promotion of the Quality of Life, San Raffaele Roma Open University. A special thanks goes to the researcher Noemi Scarpato who dealt with the construction of the DMO ontology. The present work includes the authors' individual contributions. In particular, the paragraphs 1, 3,4 and 6 have been written by Stefano Chiarenza, paragraph 2 by Rosalinda Inglisa and paragraph 5 by Aldo R.D. Accardi.

\section{REFERENCES}

Accardi, A.R.D., 2011. Il riuso della preesistenza ed il progetto d'allestimento. In: Ruggieri Tricoli, M.C., Accardi, A.R.D. (eds.). Prospettive per un museo archeologico: il caso di Modica, Quaderno n. 5 di Allestimento e Museografia e Architettura degli Interni - Offset Studio, Palermo, pp. 11-40.

Accardi, A.R.D., 2019. Le persone e le cose. Nuove strategie di comunicazione nei musei archeologici. Collana edA - Esempi di Architettura - Spazi di Riflessione, Arcane editrice, Roma.

Albisinni, P., Ippoliti, E. 2016. Virtual Museums. Communication and/Is Representation. DISEGNARECON, Virtual Museums of Architecture and Cities, vol. 9, n. 17(2016), pp. E1-E16.

Argan, G.C., 1983. Pittura e architettura. In: Enciclopedia Universale dell'Arte, X, Istituto Geografico De Agostini, Novara, pp. 626-635.

Biagetti, M.T., 2016. Un modello ontologico per l'integrazione delle informazioni del patrimonio culturale: CIDOC-CRM. Italian Journal of Library \& Information Science, 7(3), pp. 43-77.
Borst, W.N., 1997. Construction of Engineering Ontologies. Centre for Telematica and Information Technology (CTIT), Enschede, The Netherlands.

Bowen, J., 2000. The virtual museum. Museum International, 52, pp. 4-7, https://doi.org/10.1111/1468-0033.00236.

Burke, P., 2002. Testimoni oculari. Il significato storico delle immagini. Carocci, Roma.

Cardone, V., 2014. Un approccio innovativo allo studio delle prospettive architettoniche di Campania e Basilicata. In: Valenti, G. (ed). Prospettive architettoniche. Conservazione digitale, divulgazione e studio. Sapienza Università editrice, Roma, pp. 49-60.

Chiarenza, S., 2006. Architettura e spazio nelle città intarsiate. Giannini, Napoli.

Corcho, O., Fernández-López, M. and Gomez-Perez, A., 2007. Ontological Engineering: what are ontologies and how can we build them? In: Cardoso, G., Semantic Web Services: Theory, Tools and Applications. IGI Global, chapter 3, pp 44-70.

Giordano, A., 2014. La città dipinta di Canaletto, tra espansione dello spazio e visioni dinamiche. In: Buccaro, A., De Seta, C. (eds.). Città Mediterranee in Trasformazione. Identità e Immagine del Paesaggio Urbano tra Sette e Novecento. Edizioni Scientifiche Italiane, Napoli, pp. 613-622.

Kersten, T.P., Tschirschwitz, F., Deggim, S., 2017. Development of a Virtual Museum including a 4D presentation of Building Historyin Virtual Reality. ISPR Archives, vol. XLII-2/W3, pp. 361-367.

Gruber, T.R., 1993. A translation approach to portable ontology specification. Knowledge Acquisition, 5(2), pp. 199-220.

Guarino, N., 1998. Formal Ontology in Information Systems. In: Guarino, N. (ed). 1st International Conference on Formal Ontology in Information Systems (FOIS'98), Trento, Italy. IOS Press, Amsterdam, pp. 3-15.

Hernández, F.R., 2008. Building a cultural heritage ontology for Cantabria. Annual Conference of CIDOC, pp. 1-14.

https://icom.museum/en/activities/standards-

guidelines/museum-definition/ (28/06/2019).

Hyvönen, E., 2012. Publishing and using cultural heritage linked data on the semantic web. Synthesis Lectures on the Semantic Web: Theory and Technology, 2(1), pp. 1-159.

International Council of Museums (ICOM), 2007. Statutes adopted by the 22nd General Assembly in Vienna, Austria, on 24 August 2007, art. 3, Section 1,

http://archives.icom.museum/statutes.html\#3 (11/07/2019)

International Council of Museums (ICOM), 2019. Take part in creating a new museum definition,

https://icom.museum/en/activities/standardsguidelines/museum-definition/ (28/06/2019).

McCouat, P., 2015. Bernardo Bellotto and the Reconstruction of Warsaw. Journal of Art in Society, http://www.artinsociety.com/bernardo-bellotto-and-thereconstruction-of-warsaw.html (28/06/2019). 
Messina, B., Chiarenza, S., 2015. Misura e forma di architetture del passato: il ponte di Luigi Vanvitelli a Eboli. DISEGNARECON, vol. 8, n. 15 (2015), pp.141-149.

Neches, R., Fikes, R., Finin, T., Gruber, T., Patil, R., Senator, T., and Swartout, W.R., 1991. Enabling Technology for Knowledge Sharing. AI Magazine, 12(3), pp. 16-36.

Noardo, F., 2016. Architectural Heritage Ontology. Concepts and Some Practical Issues. In: Proceedings of the 2nd International Conference on Geographical Information Systems Theory, Applications and Management, volume 1, GISTAM, Roma, pp. 168-179.

Patel, M., White, M., Walczak, K. and Sayd, P., 2003. Digitisation to Presentation: Building Virtual Museum Exhibitions. Paper presented at Vision, Video and Graphics 2003, Bath, UK United Kingdom, https://researchportal.bath.ac.uk/en/publications/digitisation-topresentation-building-virtual-museum-exhibitions.

Quagliolo, M., 2002. L'accessibilità come acquisizione di informazioni dai beni culturali e ambientali: aspetti fisici, economici e culturali. In: Quagliolo, M. (ed.). Cultural Heritage Management, Accessibility to Cultural \&Natural Heritage. DRI, Roma, pp. 14-19.

Ruggieri Tricoli, M.C., 2013. Urban archaeology without the archaeology. In: Ruggieri Tricoli, M.C., Germanà, M.L., Urban archaeology enhancement. Edizioni ETS, Pisa, pp. 57-152.

Sabbatini, M., 2003. Centros De Ciencia y Museos Científicos Virtuales: Teoría y Práctica. Education in the Knowledge Society (EKS), 4(1),

http://revistas.usal.es/index.php/eks/article/view/14340

$(11 / 07 / 2019)$

Sanders, D.H., 2014. Virtual heritage: researching and visualizing the past in 3d. Journal of Eastern Mediterranean Archaeology and Heritage Studies, 2.1, pp. 30-47.

Signore, O., Bartoli, R., 1990. Implementation of a historical/geographical database with support of imprecise dates - DEXA'90: Database and Expert Systems Application. In: Tjoa, A.M., Wagner, R. (eds.). Proceedings of the International Conference, Vienna, Austria, 1990. Springer Verlag, Wien-New York, pp. 271-274.

Signore, O., Bartoli, R., Fresta, G. and Marchetti, A., 1997. Issues on historical geography In: Bearman, D., Trant, J. (eds). Museum Interactive Multimedia 1997: Cultural Heritage Systems Design and Interfaces. Selected papers from ICHIM 97. Archives \& Museum Informatics, Pittsburgh, pp. 32-37.

Sirbu, D., 2003. Digital Exploration of Unbuilt Architecture: A Non-Photorealistic Approach. In: Klinger, K.R. (ed.). Connecting >> Crossroads of Digital Discourse. ACADIA 2003 Congference Proceedings. Ball State University, Indianapolis (Indiana), pp. 235-245.

Smith, J., 2014. Virtually recreating the past. American archaeology, 16.4, pp. 13-18.

Studer, R., Richard Benjamins, V. and Fensel, D., 1998. Knowledge Engineering: Principles and Methods. Data Knowl. Eng. 25(1-2), pp. 161-197. 